\title{
Choice of method neuraxial blockade in elderly patients underwent to total hip arthroplasty
}

\author{
Babayants A.V., Tikhonova I.J., Protsenko D.N., Gelfund B.R. \\ Pirogov Russian National Research Medical University (RNRMU), Dept of \\ Anaesthesiology \& Intensive Care, Moscow Teaching Municipal Hospital \#52 Moscow, \\ Russian Federation
}

Background and Goal of Study: The majority of patients with fractures of the proximal femur are elderly people, mostly women. This category features a large number of patients with underlying chronic diseases. A comparative assessment of different types of neuraxial (spinal, epidural or spinal unilateral) at total hip arthroplasty (THA) in elderly patients with subsequent optimization of anesthesia in the surgical treatment of femoral neck fractures in geriatric patients was carried out.

Materials and methods: Survey of 108 ASA II-III patients aged 66 to 85 years who underwent total hip arthroplasty.All three groups were comparable in age, physical status, comorbidities. From anesthesia type perspective, all patients were divided into three groups: group I $(n=32)$, surgery was performed under epidural anesthesia (EPI) solution of ropivacaine $0,75 \%$,group II $(n=37)$ - spinal anesthesia $(\mathrm{S})$ with a $0,5 \%$ bupivacaine, group III $(\mathrm{n}=39)$ unilateral spinal anesthesia (US) with a $0,5 \%$ hyperbaric bupivacaine. As the criterion for estimating the frequency of hemodynamic disturbances, we looked at the frequency of ephedrine usage.

Results and discussion: In a comparative assessment of changes

in MAP it was found that the maximum reduction in SBP in the group I (EPI) occurs on the $25+6.3$ minute to level $79 \mathrm{~mm} \mathrm{Hg}$, which amounted to $25 \%$ of baseline blood pressure MAP $(p<0,05)$, in the second group II(S) the maximum reduction in MAP was noted on the $15+4.1$ minute to $71.7 \mathrm{~mm} \mathrm{Hg}$, which amounted to $32 \%$ of baseline $(p<0,05)$. In the III-rd group (US) have been reported by the smallest change in MAP from baseline: the maximum reduction of $90 \mathrm{~mm} \mathrm{Hg}$ recorded on average on the 30th minute, which amounted to $17 \%$ of baseline $(\mathrm{p}<0,05)$. There was less severe hypotension in group III- probably due to the limited sympathetic block.The incidence of hypotension in the comparative assessment of the three groups was: I(EPI), II (S) and III (US) 25\%, 29.7\% and 7.7\%, respectively. Volume infusion in groups was: $2724 \pm 845,32576,6 \pm 562,8 \mathrm{ml} \mathrm{mL}$ and $2036 \pm 57,5 \mathrm{ml}$ respectively. The total average dose of ephedrine to maintain MAP at the level no lower than $90 \mathrm{~mm}$ $\mathrm{Hg}$ in I(EPI), II (S) and III (US) was $20+2.1 \mathrm{mg}, 22+2,5 \mathrm{mg}$ and $10+1.5 \mathrm{mg}$, respectively.

Conclusion: Application of unilateral spinal anesthesia as anesthetic option for total hip arthroplasty in elderly patients promotes greater hemodynamic stability, lower infusion volume and less sympathomimetic support.

Sources:

1. Fanelli G, Borghi B, Casati A, Bertini 1, Montebugnoli M, Torri G Unilateral bupivacaine spinal anesthesia for outpatient knee arthroscopy. Italian study group on unilateral spinal anesthesia.

Can J Anesth; 2000, 47(8):746-751

2. Imbelloni LE, Gouveia MA, Vieira EM, Cordeiro JA. A randomised, double-blind comparison of three different volumes of hypobaric intrathecal bupivacaine for orthopaedic surgery.

Anaesth Int Care. 2009; 37: 242-247.

3. Kuusniemi KS, Pihlajamäki KK, Pitkänen M, Korkeila JE. A low-dose hypobaric bupivacaine spinal anesthesia for knee arthroscopie.

Reg Anesth. 1997; 22: 534-538.
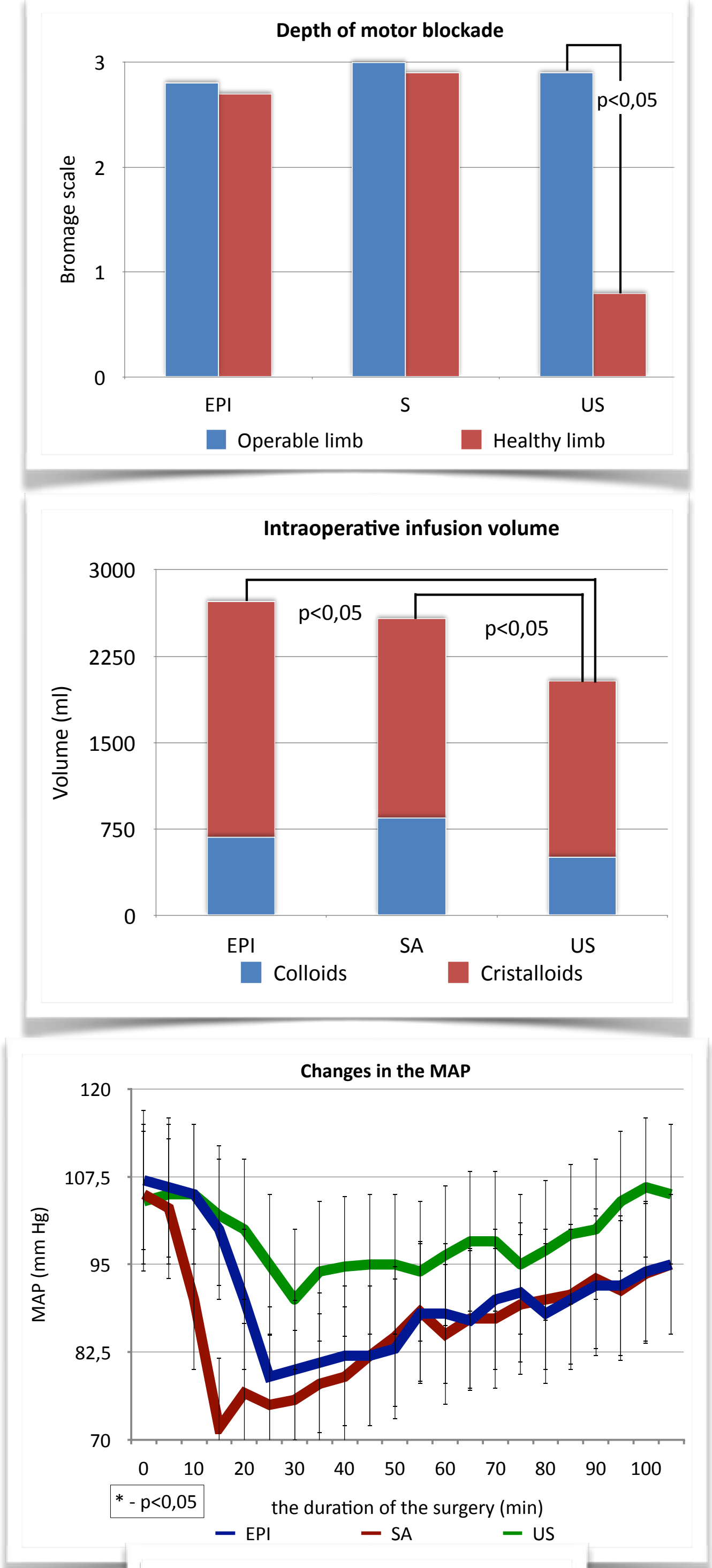

The total average dose of ephedrine
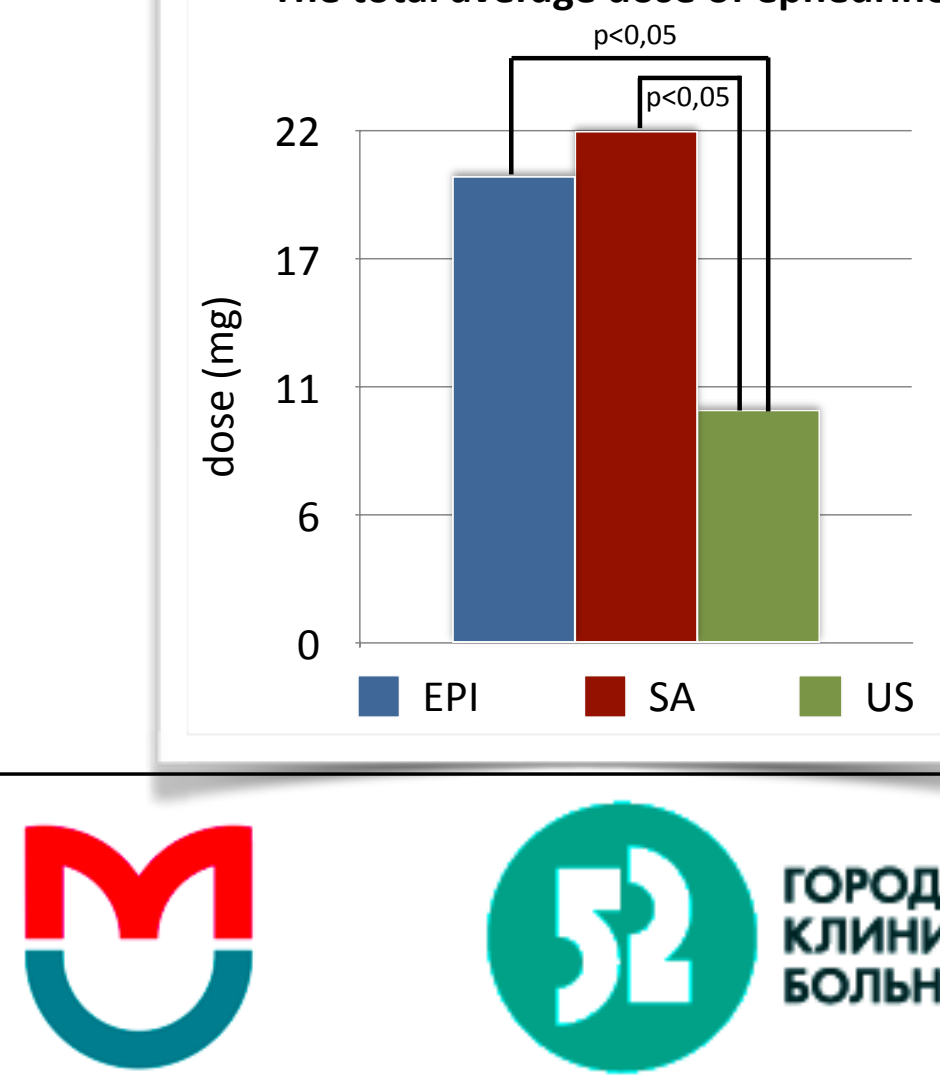

ГОРОДСКАЯ КЛИНИЧЕСКАЯ БОЛЬНИЦА №52 